\title{
Production of Thermoalkaliphilic Lipase from Geobacillus thermoleovorans DA2 and Application in Leather Industry
}

\author{
Deyaa M. Abol Fotouh, ${ }^{1}$ Reda A. Bayoumi, ${ }^{2,3}$ and Mohamed A. Hassan ${ }^{4}$ \\ ${ }^{1}$ Electronic Materials Research Department, Advanced Technology and New Materials Institute (ATNMRI), City of Scientific Research \\ and Technological Applications (SRTA-City), New Borg El-Arab City, P.O. Box 21934, Alexandria, Egypt \\ ${ }^{2}$ Biology Department, Faculty of Science and Education, Taif University, Khormah Branch, P.O. Box 21974, Taif, Saudi Arabia \\ ${ }^{3}$ Botany and Microbiology Department, Faculty of Science (Boys), Al-Azhar University, P.O. Box 11884, Cairo, Egypt \\ ${ }^{4}$ Protein Research Department, Genetic Engineering and Biotechnology Research Institute (GEBRI), City of Scientific Research and \\ Technological Applications (SRTA-City), New Borg El-Arab City, P.O. Box 21934, Alexandria, Egypt
}

Correspondence should be addressed to Deyaa M. Abol Fotouh; dabolfotouh@gmail.com and Mohamed A. Hassan; m_adelmicro@yahoo.com

Received 30 September 2015; Revised 30 November 2015; Accepted 3 December 2015

Academic Editor: Hartmut Kuhn

Copyright (C) 2016 Deyaa M. Abol Fotouh et al. This is an open access article distributed under the Creative Commons Attribution License, which permits unrestricted use, distribution, and reproduction in any medium, provided the original work is properly cited.

\begin{abstract}
Thermophilic and alkaliphilic lipases are meeting a growing global attention as their increased importance in several industrial fields. Over 23 bacterial strains, novel strain with high lipolytic activity was isolated from Southern Sinai, Egypt, and it was identified as Geobacillus thermoleovorans DA2 using $16 \mathrm{~S}$ rRNA as well as morphological and biochemical features. The lipase was produced in presence of fatty restaurant wastes as an inducing substrate. The optimized conditions for lipase production were recorded to be temperature $60^{\circ} \mathrm{C}, \mathrm{pH} \mathrm{10}$, and incubation time for $48 \mathrm{hrs}$. Enzymatic production increased when the organism was grown in a medium containing galactose as carbon source and ammonium phosphate as nitrogen source at concentrations of 1 and $0.5 \%$ (w/v), respectively. Moreover, the optimum conditions for lipase production such as substrate concentration, inoculum size, and agitation rate were found to be $10 \%(\mathrm{w} / \mathrm{v}), 4 \%(\mathrm{v} / \mathrm{v})$, and $120 \mathrm{rpm}$, respectively. The TA lipase with Triton X-100 had the best degreasing agent by lowering the total lipid content to $2.6 \%$ as compared to kerosene $(7.5 \%)$ or the sole crude enzyme ( $8.9 \%)$. It can be concluded that the chemical leather process can be substituted with TA lipase for boosting the quality of leather and reducing the environmental hazards.
\end{abstract}

\section{Introduction}

Lipases (triacylglycerol acylhydrolases, E.C. 3.1.1.3) are ubiquitous enzymes of considerable physiological significance and industrial potential [1]. Lipases catalyze the hydrolysis of triacylglycerols to glycerol and free fatty acids. Today, lipases are the choice of biocatalyst as they show unique chemo-, regio-, enantioselectivities, which enable the production of novel drugs, agrochemicals, and fine products [2].

Due to the ability of many lipases to perform both hydrolytic and synthetic reactions, they find immense applications in industries like foods, detergents, pharmaceuticals, leather, cosmetics, textile, dairy, and even biodiesel $[3,4]$.

Lipases are widely present in plants and animals, but almost all the commercially available lipases are usually obtained from microorganisms that produce a wide variety of extracellular lipases [5].

Cost of lipase production process was considered as a major obstacle in the industries. Therefore, many efforts are being made to use wastes as raw materials for lipase production. Agricultural residues for lipase production as well as other value added products would hold a prominent position in future biotechnologies, mainly because of its ecofriendliness and flexibility to both developing and developed countries. Several residues such as oil cakes, fibrous residues, and industrial effluent have increasing attention as abundant and cheap renewable feedstock $[5,6]$. Enzymes from thermophiles and alkaliphiles have become the subject of special interest for biotechnological applications due to their high stability at adverse operational and/or storage conditions [7]. 
Many advantages were earned for carrying out biotechnological and industrial processes in high temperatures: high solubility of substrates (in particular for poorly soluble or polymeric molecules) resulting in higher product yield, higher reaction rates, increased availability of substrates, decreased risk of microbial contamination, and lower viscosity of reaction mixtures which in turn reduces the costs related to pumping, filtration, and centrifugation, and saving a great power cost would be exploited for cooling $[8,9]$.

In the present study, a detailed description of isolation, identification, and optimization of TA lipase production conditions from $G$. thermoleovorans DA2 will be demonstrated. An attempt to utilize restaurant fatty wastes as the main substrate for lipase production was carried out, which may raise the lipolytic activity and decrease the overall cost of the production process. In addition, this approach has a great environmental endeavor through minimizing the ecological hazards accompanied with the accumulation of wastes.

The application of TA lipase from G. thermoleovorans DA2 in leather tanning process as a degreasing agent replaced the commonly utilized organic solvent (Kerosene). Kanagaraj et al. reported that it is fundamental to add hydrolytic enzymes such as lipases and proteases in the soaking step for helping the fat degradation and raise the leather quality [10].

Substitution of the traditional chemical tanning processing with more ecofriendly treating procedures, for example, the enzymatic steps, became a necessity because of the recorded environmental hazards resulting from the pollution of water, careless disposal of solid wastes, and gaseous emissions [11].

\section{Materials and Methods}

2.1. Bacterial Strain. A wide variety of samples were collected from many localities in Egypt, including desert and hot springs of Southern Sinai, Wadi El-Natron swamps, desert of Qina and Suez governorates, and the soil of El-Basateen slaughter house.

All samples were suspended in sterilized saline solution $(0.85 \% \mathrm{w} / \mathrm{v})$ which were cultured on plates of nutrient agar medium with $\mathrm{pH} 9$ and incubated at $65^{\circ} \mathrm{C}$ for $48 \mathrm{hrs}$. The separated colonies had undergone a series of (agar streak method) for purification, and the morphological characteristics of each isolate were investigated. The purpose of this method was to isolate the thermoalkalophilic microorganisms.

\subsection{Screening}

2.2.1. Qualitative Assay. All strains were screened for investigating their lipase activity on agar plates containing Rhodamine B $0.001 \%$ (w/v), nutrient broth $0.8 \%$ (w/v), $\mathrm{NaCl} 0.4 \%$ $(\mathrm{w} / \mathrm{v})$, agar $1 \%(\mathrm{w} / \mathrm{v})$, and olive oil $3 \%$, in distilled water and the $\mathrm{pH}$ was adjusted to be 9 [12].

Plates were incubated at $65^{\circ} \mathrm{C}$ for $18 \mathrm{hrs}$ and the lipase activity was identified as an orange halo zone around colonies under UV light at $350 \mathrm{~nm}$.
2.2.2. Quantitative Assay. To detect the most potent thermoalkaliphilic lipase producing bacteria, all bacterial isolates were grown on medium composed of yeast extract $1 \mathrm{~g}$; olive oil $10 \mathrm{~mL}$; gum Arabic $10 \mathrm{~g}$; $\mathrm{CaCl}_{2} 1 \mathrm{~g}$; and mineral salt solution $1 \mathrm{~mL}$ per liter. The medium $\mathrm{pH}$ is initially adjusted at 9 by using $6 \mathrm{~N} \mathrm{NaOH}$ and incubated at $65^{\circ} \mathrm{C}$ and $100 \mathrm{rpm}$ for $18 \mathrm{hrs}$. The most potent thermoalkaliphilic lipase producing isolate was purified by "agar streak method" and underwent biochemical investigations and it was identified by $16 \mathrm{~S}$ rRNA technique.

2.2.3. Bacterial Identification. The bacterial isolate was identified using $16 \mathrm{~S}$ rRNA sequence. The genomic DNA was extracted by the following method which was described by Sambrook et al. [13].

The PCR amplification was carried out according to Hassan et al. and Abdou and Hassan. The reaction was performed using forwarded $16 \mathrm{~S}$ rRNA primer $\left(5^{\prime}\right.$-AAATGGAGGAAGGTGGGGAT-3') and reverse $16 \mathrm{~S}$ rRNA primer $\left(5^{\prime}\right.$-AGGAGGTGATCCAACCGCA- $\left.{ }^{\prime}\right)$. The PCR machine (TECHNE TC-3000, FTC3/02) was programmed as follows: 3 min denaturation at $95^{\circ} \mathrm{C}$, followed by 35 cycles that consisted of $1 \mathrm{~min}$ at $95^{\circ} \mathrm{C}, 1 \mathrm{~min}$ at $58^{\circ} \mathrm{C}$, and $1 \mathrm{~min}$ at $72^{\circ} \mathrm{C}$ and the final extension was $10 \mathrm{~min}$ at $72^{\circ} \mathrm{C}[14,15]$.

The PCR product was cleaned up for sequencing using Qiagen kit for DNA purification from aqueous PCR. DNA sequencing method which was developed by Sanger et al. was carried out using 3130X DNA Sequencer (Genetic Analyzer, Applied Biosystems, Hitachi, Japan) [16].

2.2.4. Sequence Analysis and Phylogenetic Tree Construction. Similarity of the obtained nucleotide sequence was performed by basic local alignment search tool (BLAST) against reference sequences available in National Center for Biotechnology Information GenBank (NCBI GenBank). The reference sequences were collected from GenBank and the alignments using Clastal W were performed for constructing the phylogenetic tree using MEGA 5 software version 5.1 [17].

2.3. Lipase Production. G. thermoleovorans DA2 was grown on a liquid production medium containing (\%, w/v) yeast extract, $0.1 \mathrm{~g} ; \mathrm{NaNO}_{3}, 0.2 \mathrm{~g} ; \mathrm{KH}_{2} \mathrm{PO}_{4}, 0.1 \mathrm{~g} ; \mathrm{MgSO}_{4} \cdot 7 \mathrm{H}_{2} \mathrm{O}$, $0.05 \mathrm{~g} ; \mathrm{KCl}, 0.05 \mathrm{~g}$; and $\mathrm{CaCl}_{2}, 0.1 \mathrm{~g}$, supplemented with $1 \mathrm{~g}$ of fatty restaurant wastes.

The medium was adjusted at $\mathrm{pH} 9$ ( $\mathrm{pH}-$ Meter Model420A Orion Co., USA) and $100 \mathrm{~mL}$ of medium in $500 \mathrm{~mL}$ Erlenmeyer flasks was inoculated with $G$. thermoleovorans DA2 and incubated at $65^{\circ} \mathrm{C}$ and $100 \mathrm{rpm}$ for $18 \mathrm{hrs}$ on a rotary shaker (Innova J-25 New Brunswick scientific, USA).

2.4. Assay of Thermoalkaliphilic Lipase Activity. Lipase activity was detected by a spectrophotometric assay using $p$-nitrophenyl laurate ( $p$ NPL) as a substrate according to CastroOchoa et al. and Amara et al. with slight modifications. In brief, the reaction mixture consisted of $0.1 \mathrm{~mL}$ enzyme extract, $0.8 \mathrm{~mL} 0.1 \mathrm{M}$ phosphate buffer ( $\mathrm{pH} 8$ ), and $0.1 \mathrm{~mL} 0.01 \mathrm{M}$ $p N P L$ in isopropanol. The hydrolytic reaction was carried out at $60^{\circ} \mathrm{C}$ for $30 \mathrm{~min}$ and then terminated by $0.25 \mathrm{~mL}$ of $0.1 \mathrm{M}$ 
$\mathrm{Na}_{2} \mathrm{CO}_{3}$ added. The mixture was centrifuged at $10,000 \mathrm{rpm}$ for $15 \mathrm{~min}$ and the absorbance was determined at $410 \mathrm{~nm}$ using spectrophotometer (spectrophotometer: Lambda EZ 201 Perkin Elmer, USA). One unit of lipase activity was defined as the amount of enzyme that caused the release of $1 \mu \mathrm{mol}$ of $p$-nitrophenol (molar absorption coefficient $4.6 \mathrm{mM}^{-1} \mathrm{~cm}^{-1}$ ) from $p$ NP-laurate in $30 \mathrm{~min}$ under test conditions $[18,19]$.

2.5. Determination of Protein Content. Protein content was determined according to Lowry Method [20].

2.6. Optimization of Various Production Conditions of TA Lipase from G. thermoleovorans DA2. Several experiments were conducted to study the effect of physical and nutrients on culture conditions for TA lipase production by G. thermoleovorans DA2. All the previously mentioned production conditions were investigated throughout the following experiments.

2.6.1. Effect of Incubation Temperature on Production of TA Lipase from G. thermoleovorans DA2. Most favorable production temperature was studied by incubating the inoculated production medium at varying temperatures $(50,55,60$, $65,70,75,80,85$, and $90^{\circ} \mathrm{C}$ ). The culture filtrate was used for the lipase activity.

2.6.2. Effect of $p H$ of the Medium on the Production of TA Lipase from G. thermoleovorans DA2. For optimization of production $\mathrm{pH}$, the production medium of different $\mathrm{pH}$, namely, $6,7,8,9,10,11$, and 12 , was inoculated with culture and incubated in shaker for $18 \mathrm{hrs}$ at $65^{\circ} \mathrm{C}$ and lipase activity of culture filtrate was determined.

2.6.3. Effect of Incubation Time on Production of TA Lipase from $G$. thermoleovorans DA2. To optimize incubation time for the maximum production of lipase, the production medium was incubated at $60^{\circ} \mathrm{C}$ in the shaker for $12,18,24$, $36,48,56$, and $72 \mathrm{hrs}$.

2.6.4. Effect of Carbon Source on Production of Lipase from G. thermoleovorans DA2. Various carbon sources such as glucose, galactose, xylose, ribose, rhamnose, melezitose, sucrose, lactose, maltose, cellobiose, sorbitol, mannitol, and inulin were used in the production medium at the concentration of $1 \%(\mathrm{w} / \mathrm{v})$ to check the effect of carbon source on lipase production. The medium without carbon source served as control and the culture filtrate was assayed for enzyme activity.

2.6.5. Effect of Nitrogen Source on Production of TA Lipase from $G$. thermoleovorans DA2. To study the effect of nitrogen source, various nitrogen sources such as ammonium chloride, ammonium sulphate, ammonium nitrate, ammonium molybdate, ammonium phosphate, sodium nitrite, urea, calcium nitrate, potassium nitrate, and peptone were conducted in the production medium at the concentration of $0.5 \%(\mathrm{w} / \mathrm{v})$. The main medium included sodium nitrate only served as control. The culture filtrate was assayed for enzyme activity.
2.6.6. Effect of Substrate Concentration on Production of Lipase from $G$. thermoleovorans DA2. The effect of substrate concentration on the production of TA lipase was determined by varying the concentration of fatty restaurant wastes, that is, $0.25,0.5,1,2,5,10,20$, and $40 \%(\mathrm{w} / \mathrm{v})$.

2.6.7. Effect of Inoculum Size on Production of Lipase from G. thermoleovorans DA2. Heavy cell suspension of G. thermoleovorans DA2 was prepared by growing bacterial isolate on nutrient broth and limiting growth level at $3 \times$ $10^{7} \mathrm{CFU} \cdot \mathrm{mL}^{-1}$. Different inocula sizes of culture including $0.25,0.5,1,2,4,5$, and $10 \%(\mathrm{v} / \mathrm{v})$ were applied.

2.6.8. Effect of Agitation Rate on Production of TA Lipase from $G$. thermoleovorans DA2. To optimize the agitation rate for maximum lipase production, the inoculated production medium was agitated at different rotations per minute (rpm) such as $40,80,120$, and $150 \mathrm{rpm}$. The culture filtrate was used to check the enzyme activity.

2.7. Application of TA Lipase from $G$. thermoleovorans DA2 in Degreasing of Leather. The crude TA lipase from G. thermoleovorans DA2 was used as degreaser agent in leather industry as compared to traditional methods which depends upon solvents and surfactants.

2.7.1. Preparation of Skin Samples. A piece of sheep skin was obtained after it had undergone the common processing steps, that is, liming, dehairing, and bating. Eight skin pieces about $5 \times 5 \mathrm{~cm}$ dimension were cut and divided into 4 groups (each of 2 pieces):

Group (A): the skin was soaked in $50 \mathrm{~mL}$ (Kerosene) and was incubated at $25^{\circ} \mathrm{C}$ as a traditional method.

Group (B): the skin was immersed in $50 \mathrm{~mL}$ of $10 \%$ of the crude TA lipase and was incubated at $60^{\circ} \mathrm{C}$.

Group (C): the skin was treated with a mixture of crude TA lipase (10\%) + Kerosene in $4: 1$ ratio and was incubated at $60^{\circ} \mathrm{C}$.

Group (D): the skin was bathed in a mixture of crude TA lipase (10\%) + Triton X-100 in $10: 1$ ratios and was incubated at $60^{\circ} \mathrm{C}$.

All groups of skin were treated for $2 \mathrm{hrs}$ then; the skin was collected and dried [21].

2.7.2. Total Lipid Measurement Technique. Total lipid of the treated skin pieces were measured relying on Soxhlet apparatus [22]. The obtained values were then compared with the lipid content of the control.

\section{Results}

3.1. Bacterial Strain Selection and Identification. Out of seven isolates the most efficient lipase producer was isolated from desert of southern Sinai based on enzyme assay method and it was identified using 16S rRNA and selected for further studies. 


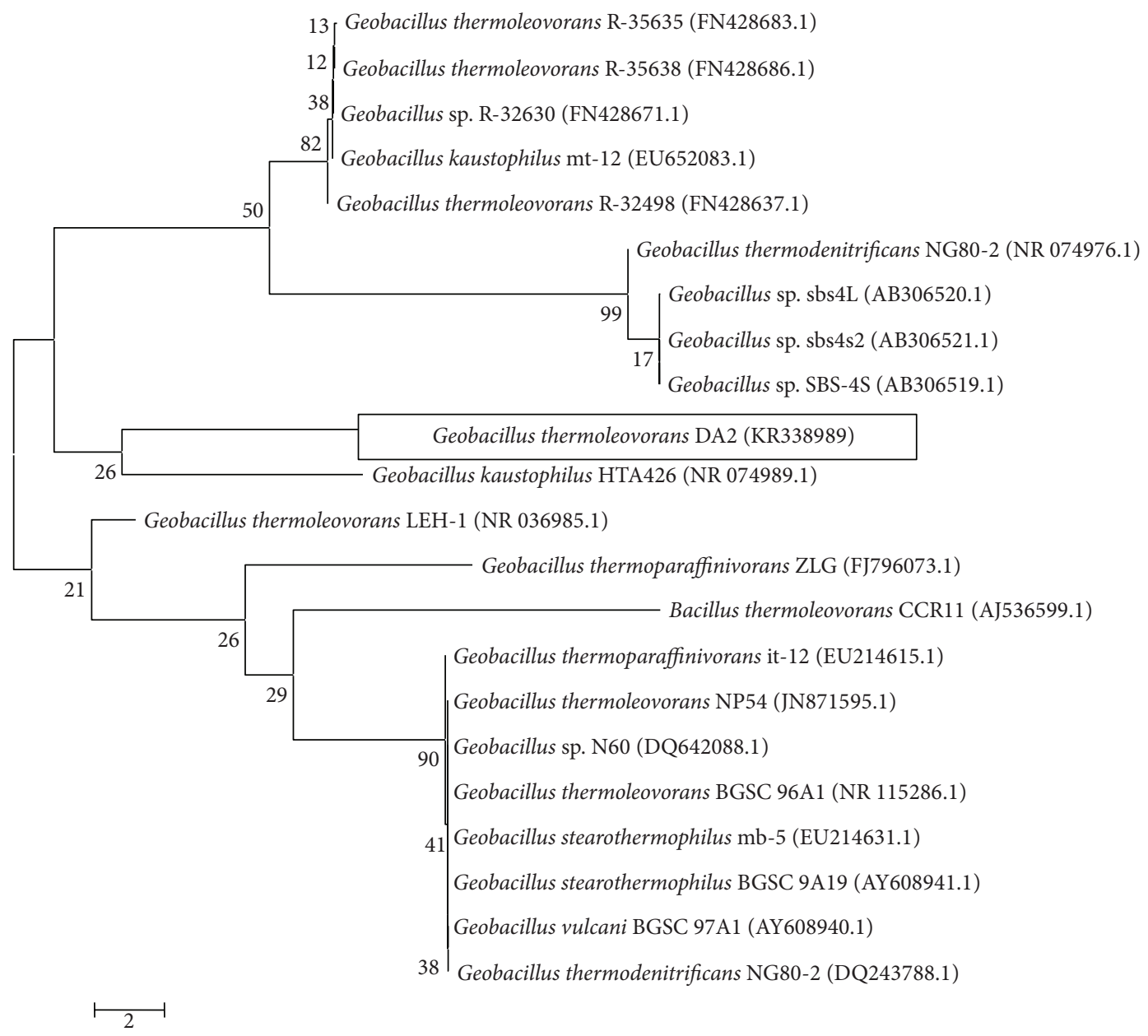

FIGURE 1: Phylogenetic position of Geobacillus thermoleovorans DA2 within the genus Geobacillus. The branching pattern was generated by neighbor-joining tree method and the GenBank accession numbers of the 16S rRNA nucleotide sequences are indicated in brackets. The bar indicates a Jukes-Cantor distance of 2.

3.2. Bacterial Identification by $16 S \mathrm{rRNA}$. The amplified $16 \mathrm{~S}$ rRNA gene fragment was investigated using DNA ladder (Gene ruler $50 \mathrm{bp}-1031 \mathrm{bp}$ DNA ladder) and it was $380 \mathrm{bp}$.

The BLAST algorithm was used to retrieve for homologous sequences in GenBank to the obtained 16S rRNA sequence. The bacterial isolate revealed $99 \%$ identity to full genome of Geobacillus thermoleovorans, Geobacillus stearothermophilus, G. thermoparaffinivorans, G. thermodenitrificans, and G. kaustophilus. Based on the morphological, biochemical, and molecular characteristics, the isolate was identified and released in NCBI GenBank as Geobacillus thermoleovorans DA2 under the accession numbers (KR338990), and the branching pattern was analyzed by 500 bootstrap replicates as in Figure 1. G. thermoleovorans DA2 is an aerobic, spore-forming, nonmotile rod able to grow at high temperatures $\left(50-80^{\circ} \mathrm{C}\right)$ with an optimum growth at $65^{\circ} \mathrm{C}$.

\subsection{Optimization of Production Conditions of TA Lipase from G. thermoleovorans DA2}

3.3.1. Effect of Incubation Temperature on Production of TA Lipase from $G$. thermoleovorans DA2. Most suitable temperature for maximum production of TA lipase $(146.85 \mathrm{U} / \mathrm{mL})$ from G. thermoleovorans DA2 was found to be $60^{\circ} \mathrm{C}$ as shown in Figure 2(a).

3.3.2. Effect of $p H$ of the Medium on Production of TA Lipase from $G$. thermoleovorans $D A 2$. The maximum production of TA lipase from $G$. thermoleovorans DA2 was observed at $\mathrm{pH} 10(157.15 \mathrm{U} / \mathrm{mL})$ and after that, the lipase activity was decreased with increasing the $\mathrm{pH}$ values as shown in Figure 2(b).

3.3.3. Optimization of Incubation Time for Production of TA Lipase from $G$. thermoleovorans DA2. The maximum production of lipase was observed at $48 \mathrm{hrs}(248.11 \mathrm{U} / \mathrm{mL})$. Optimal incubation time was found to be $48 \mathrm{hrs}$ corresponding to maximum enzyme activity and after this decline in enzyme activity was observed (Figure 2(c)).

3.3.4. Effect of Carbon Source on Production of TA Lipase from G. thermoleovorans DA2. Maximum production of TA lipase was obtained from the medium which was supplemented 


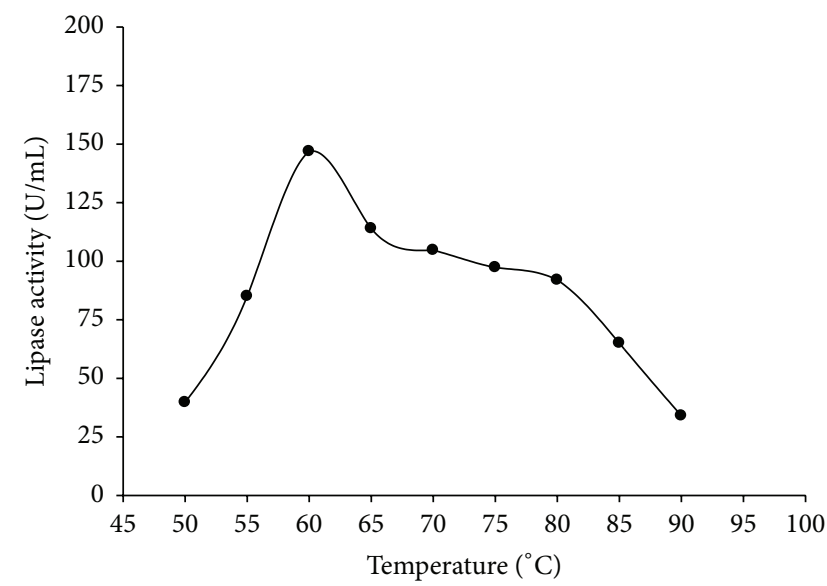

(a)

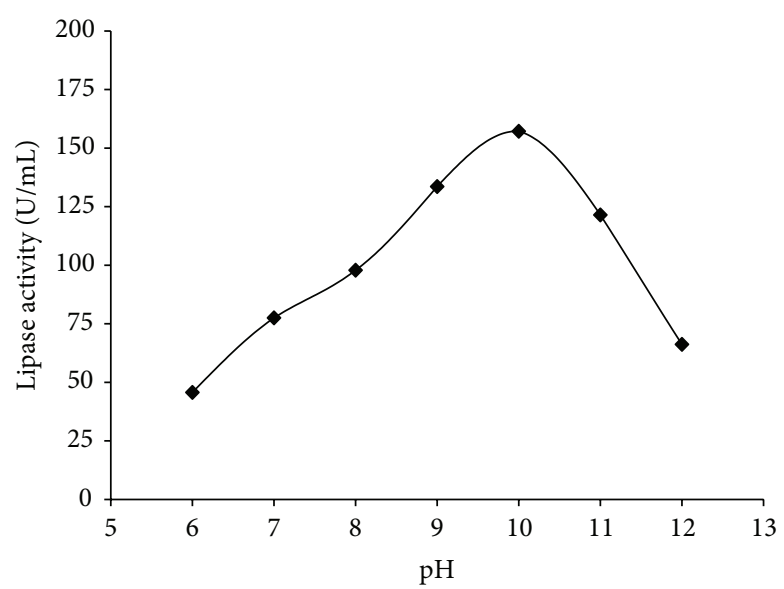

(b)

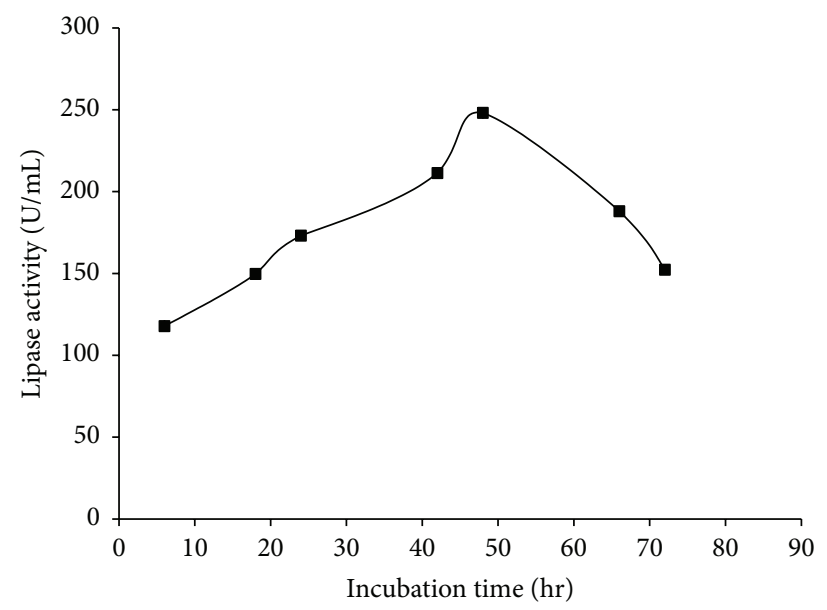

(c)

Figure 2: (a) Effect of incubation temperature on production of TA lipase from G. thermoleovorans DA2. (b) Effect of pH on production of TA lipase from G. thermoleovorans DA2. (c) Effect of incubation time on production of TA lipase from G. thermoleovorans DA2.

with galactose (1\%) as carbon source giving enzyme activity of $701.86 \mathrm{U} / \mathrm{mL}$ (Figure 3(a)).

\subsubsection{Effect of Nitrogen Source on Production of TA Lipase from} $G$. thermoleovorans DA2. The lipase production was highest $(843.04 \mathrm{U} / \mathrm{mL})$ in medium containing ammonium phosphate at a concentration $(0.5 \%)$ as nitrogen source (Figure $3(\mathrm{~b})$ ).

\subsubsection{Effect of Substrate Concentration on Production of TA} Lipase from $G$. thermoleovorans DA2. Maximum enzyme activity $(892.43 \mathrm{U} / \mathrm{mL})$ was observed with $10 \%(\mathrm{w} / \mathrm{v})$ fatty restaurant wastes (Figure 3(c)).

3.3.7. Optimization of Inoculum Size for Production of TA Lipase from $G$. thermoleovorans DA2. Figure 3(d) reveals that the inoculum size $(4 \%, v / v)$ gave the maximum lipase production with an activity of $917.23 \mathrm{U} / \mathrm{mL}$.

3.3.8. Effect of Agitation Rate on Production of TA Lipase from $G$. thermoleovorans DA2. The maximum lipase activity $(1021.91 \mathrm{U} / \mathrm{mL})$ was observed at $120 \mathrm{rpm}$ as shown in Figure 3(e).
3.4. Application of TA Lipase in Degreasing of Leather. The thermoalkaliphilic lipase from $G$. thermoleovorans DA2 plus Triton X-100 was the most efficient leather degreasing agent where the total lipid content decreased from $17.5 \%$ to $2.6 \%$ as shown in Table 1.

The mixture of TA lipase plus kerosene decreased the total lipid content to $5.7 \%$; so it came in second level.

\section{Discussion}

The applications of lipases are constantly increased in industrial and biotechnological fields; therefore, that should be supported by discovering novel lipase types with improved characters. The common about enzymes is their sensitivity to adverse conditions such as high temperature, extreme acidity and/or alkalinity, drought, and high salinity, but extremozymes, enzymes derived from extremophilic microorganisms, are an attractive alternative to tuning a given biocatalyst for a specific industrial application. They are capable of catalyzing their respective reactions in nonaqueous environments, water/solvent mixtures, at extremely high pressures, acidic and alkaline $\mathrm{pH}$, at temperatures up to $140^{\circ} \mathrm{C}$, or near 


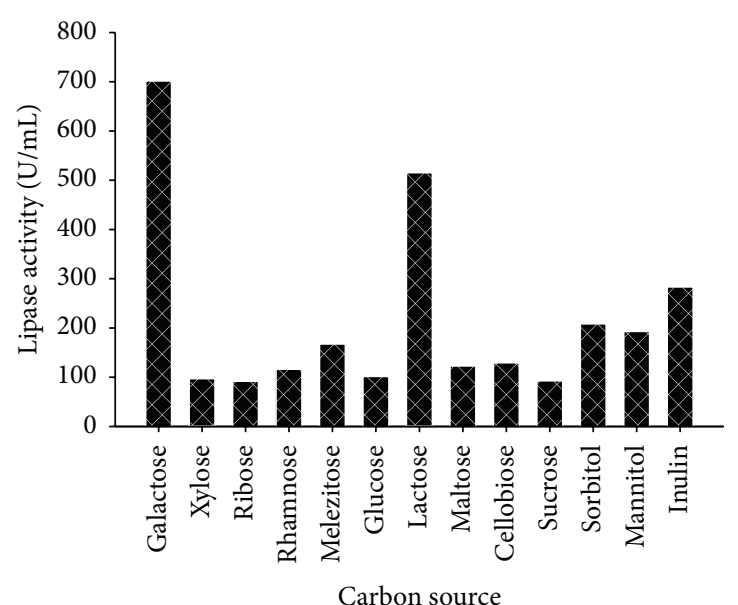

(a)

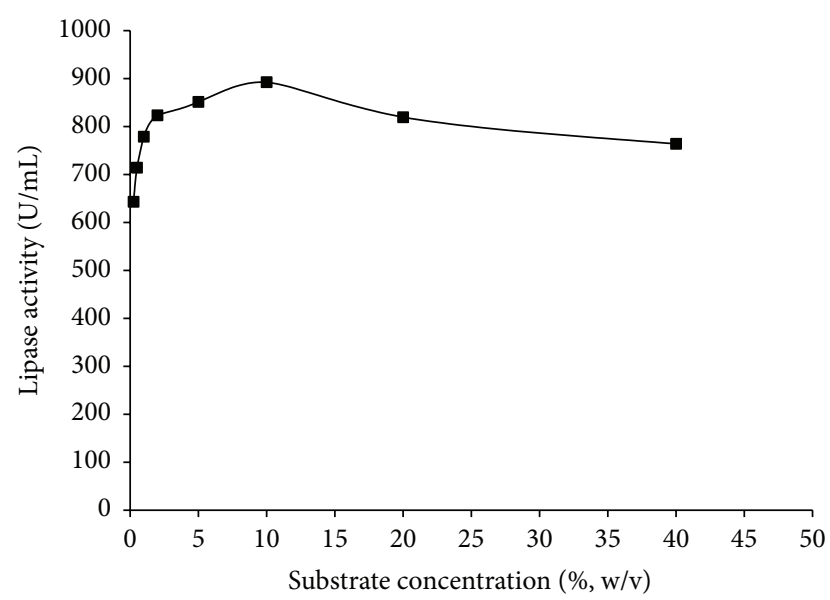

(c)

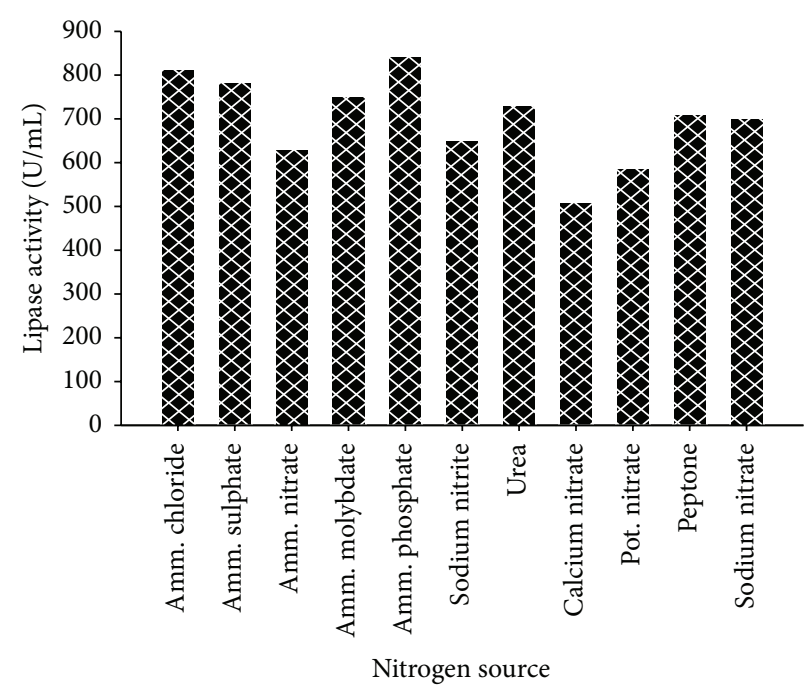

(b)

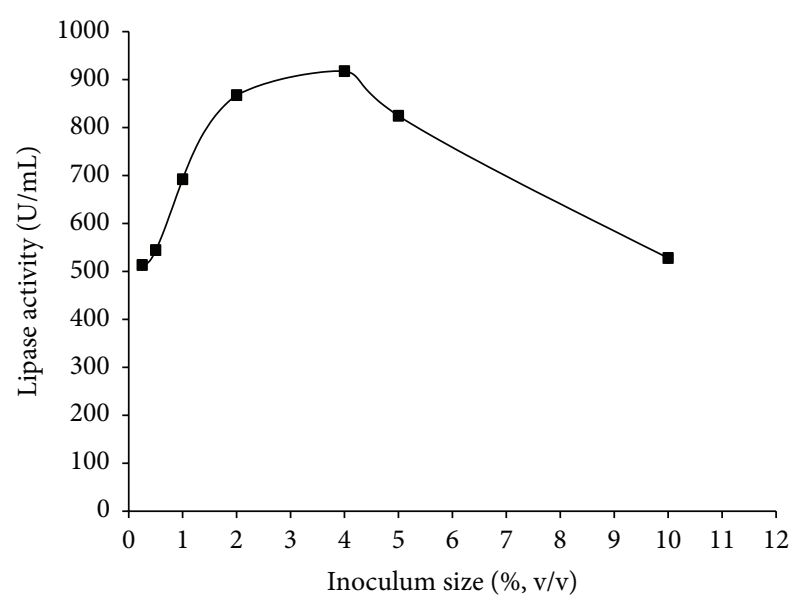

(d)

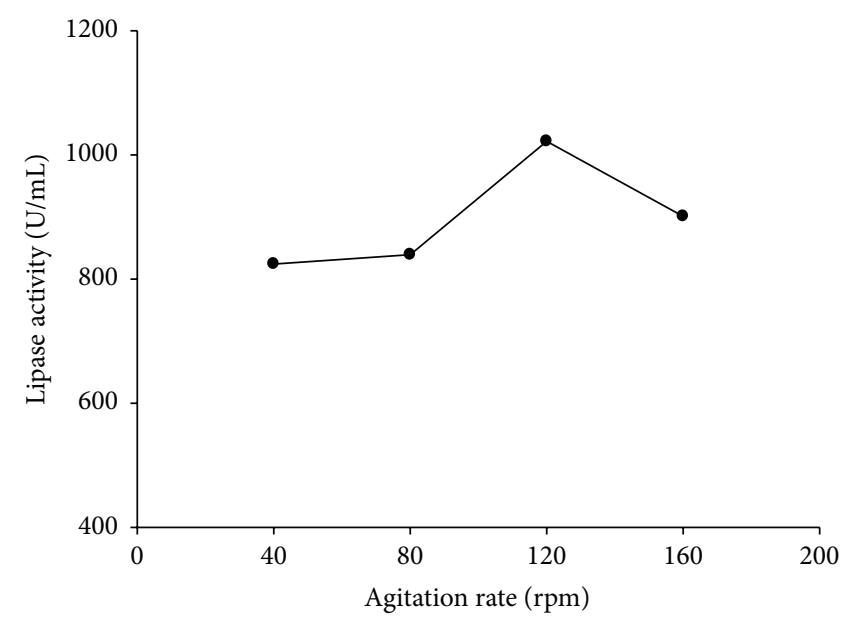

(e)

FIGURE 3: (a) Effect of carbon source on production of lipase from G. thermoleovorans DA2. (b) Effect of nitrogen source on production of lipase from $G$. thermoleovorans DA2. (c) Effect of substrate concentration on production of TA lipase from G. thermoleovorans DA2. (d) Effect of inoculum size on production of TA lipase from G. thermoleovorans DA2. (e) Effect of agitation rate on production of lipase from Geobacillus thermoleovorans DA2. 
TABLE 1: Effect of using the TA lipase from G. thermoleovorans DA2 as a degreasing agent and the total lipid content of leather samples.

\begin{tabular}{lcc}
\hline Group of leather samples & Type of leather treatment & Total lipid content (\%) \\
\hline & Control (without treatment) & 17.50 \\
Group (A) & Organic solvent (Kerosene) & 7.50 \\
Group (B) & $10 \%$ crude lipase produced by G. thermoleovorans DA2 & 8.90 \\
Group (C) & $10 \%$ crude lipase produced by G. thermoleovorans DA2 + Kerosene & 5.70 \\
Group (D) & $10 \%$ crude lipase produced by G. thermoleovorans DA2 + Triton X-100 & 2.60 \\
\hline
\end{tabular}

the freezing point of water [23]. The present investigation is an attempt to discover novel bacterial strains with the capability of producing lipases able to tolerate high temperature and high alkalinity as well. Seven of twenty three strains showed different lipolytic activities in incubation temperature $65^{\circ} \mathrm{C}$ and $\mathrm{pH}$ 9; the most potent producing strain is identified as $G$. thermoleovorans DA2 selected to further studies as the most promising source of thermoalkaliphilic lipase.

Optimum temperature in the present investigation came in correspondence with the optimum temperature for lipase produced by G. stearothermophilus strain-5 [24]. On the other hand, the temperature for the highest production of lipase by G. thermodenitrificans $\mathrm{AZ} 1$ was $55^{\circ} \mathrm{C}$ [25].

Optimum $\mathrm{pH}$ value for the present study suggests more alkaliphilic behavior comparing to lipases produced by Geobacillus thermoleovorans CCR11 and the alkaliphilic Bacillus sp. (KS4) which was found to give their highest lipase productions at $\mathrm{pH} 8[26,27]$. Berekaa et al. reported that the optimum $\mathrm{pH}$ for lipase production by $\mathrm{G}$. stearothermophilus strain-5 was 7 [28].

G. thermoleovorans DA2 was found to consume $48 \mathrm{hrs}$ to give its maximum production of TA lipase comparing to Bacillus thermoleovorans CCR11 which is recorded to produce the highest lipase rate after $44 \mathrm{hrs}$, while the highest production of lipase by the thermophilic strain Bacillus sp. strain 42 was recorded after $72 \mathrm{hrs}[26,29]$.

Galactose was found to be the most supportive carbon source for the TA lipase production by G. thermoleovorans DA2, suggesting high ability of the strain to uptake and utilize the monosaccharide galactose in the metabolic processes of lipase production as the lactose disaccharide was the second optimum carbon source. Glycerol was found to be the most inducing carbon source for lipase production by G. stearothermophilus strain-5, while it is the highest lipase production by $B$. subtilis ZR-1 supported by the sole olive oil [12, 28].

Peptone was the most supportive nitrogen source for lipase production by Bacillus sp. LBN2 [30]. In contrast, mix of yeast extract and peptone was the best for the production of thermoalkaliphilic lipase by B. coagulans BTS-3 [31]. Moreover, sole yeast extract was the best for lipase produced by B. licheniformis MTCC-10498 [32].

Abd El Rahman found that $12.5 \%$ of the slaughter house waste was the optimum substrate concentration for lipase production by B. stearothermophilus B-78, while Gayathri et al. have reported that $2 \%$ of palm oil was the optimum concentration for lipase production by B. stearothermophilus [33, 34].

Ten percent $(10 \%, \mathrm{v} / \mathrm{v})$ was the optimum inoculum for lipase production by B. licheniformis MTCC-10498 [32].
However, Bacillus flexus XJU-1 gave the best production of lipase depending on $2 \%(\mathrm{v} / \mathrm{v})$ inoculum size, while $6 \%(\mathrm{v} / \mathrm{v})$ was the optimum inoculum size for the best lipase production by Pseudomonas gessardii $[35,36]$.

The optimum revolution per minute for the maximum production of TA lipase by $G$. thermoleovorans DA2 was found to be $120 \mathrm{rpm}$, which came in complete accordance with the optimum agitation rate for highest lipase production by B. licheniformis MTCC-10498 [32], while Veerapagu et al. reported that the optimized value for greatest lipase production by Pseudomonas gessardii was $160 \mathrm{rpm}$ [36].

Once samples of sheep leather were treated with TA lipase produced by the strain $G$. thermoleovorans DA2 mixed with Triton X-100, fatty content of the leather depleted from $17.5 \%$ to $2.5 \%$. This may be due to the elevated processing temperature which takes a hand in destroying the walls of skin fat cells and increase solubility of the fat content very well. Moreover, Triton X-100 had supportive effect in reducing the surface tension of the lipids and facilitated the enzyme efficacy. Saran et al. recorded degreasing rate more than $95 \%$ by $5-10 \%$ mesophilic lipase enzyme produced by Bacillus subtilis solely after treating for $12 \mathrm{hrs}$ [11].

Moreover, their interpretations came in complete accordance with our observations about the higher quality, appearance, and smoothness levels of the enzyme-treated leather compared to chemically processed skin. The obtained results are suggesting that advanced efforts to replace the ecohazardous traditional chemical tanning process with the green enzymatic techniques are worthy to be achieved.

\section{Conclusion}

In the present study, thermoalkaliphilic lipase was produced from the new bacterial isolate which was identified using the sequence of 16S rRNA gene and biochemical tests as Geobacillus thermoleovorans DA2. Wide ranges of growth factors were studied for maximizing TA lipase enzyme. The production of TA lipase with high amount using cheap substrate (fatty restaurant wastes) made the production process costeffective. The results exhibited the potential application of the TA lipase in leather industry as a degreaser suggesting more ecofriendly tanning processes in the future.

\section{Conflict of Interests}

The authors have no conflict of interests to declare. 


\section{References}

[1] R. Sharma, Y. Chisti, and U. C. Banerjee, "Production, purification, characterization, and applications of lipases," Biotechnology Advances, vol. 19, no. 8, pp. 627-662, 2001.

[2] R. Kaushik, S. Saran, J. Isar, and R. K. Saxena, "Statistical optimization of medium components and growth conditions by response surface methodology to enhance lipase production by Aspergillus carneus," Journal of Molecular Catalysis B: Enzymatic, vol. 40, no. 3-4, pp. 121-126, 2006.

[3] F. Hasan, A. A. Shah, and A. Hameed, "Industrial applications of microbial lipases," Enzyme and Microbial Technology, vol. 39, no. 2, pp. 235-251, 2006.

[4] A. Robles-Medina, P. A. González-Moreno, L. Esteban-Cerdán, and E. Molina-Grima, "Biocatalysis: towards ever greener biodiesel production," Biotechnology Advances, vol. 27, no. 4, pp. 398-408, 2009.

[5] A. Salihu, M. Z. Alam, M. I. AbdulKarim, and H. M. Salleh, "Lipase production: an insight in the utilization of renewable agricultural residues," Resources, Conservation and Recycling, vol. 58, pp. 36-44, 2012.

[6] J. Sahasrabudhe, S. Palshikar, A. Goja, and C. Kulkarni, "Use of ghee residue as a substrate for microbial lipase production," International Journal of Scientific \& Technology Research, vol. 1, no. 10, pp. 61-64, 2012.

[7] B. P. Golaki, S. Aminzadeh, A. A. Karkhane et al., "Cloning, expression, purification, and characterization of lipase 3646 from thermophilic indigenous Cohnella sp. A01," Protein Expression and Purification, vol. 109, pp. 120-126, 2015.

[8] A. Trincone, "Marine biocatalysts: enzymatic features and applications," Marine Drugs, vol. 9, no. 4, pp. 478-499, 2011.

[9] S. P. S. Bisht and S. Panda, "Isolation and identification of new lipolytic thermophilic bacteria from an Indian hot spring," International Journal of Pharma and Bio Sciences, vol. 2, pp. 229235, 2011.

[10] J. Kanagaraj, T. Senthilvelan, R. C. Panda, and S. Kavitha, "Ecofriendly waste management strategies for greener environment towards sustainable development in leather industry: a comprehensive review," Journal of Cleaner Production, vol. 89, pp. 1-17, 2015.

[11] S. Saran, R. V. Mahajan, R. Kaushik, J. Isar, and R. K. Saxena, "Enzyme mediated beam house operations of leather industry: a needed step towards greener technology," Journal of Cleaner Production, vol. 54, pp. 315-322, 2013.

[12] M. Rabbani, M. R. Bagherinejad, H. M. Sadeghi et al., "Isolation and characterization of novel thermophilic lipase-secreting bacteria," Brazilian Journal of Microbiology, vol. 44, no. 4, pp. 1113-1119, 2013.

[13] J. Sambrook, E. F. Fritsch, and T. Maniatis, Molecular Cloning: A Laboratory Manual, Cold Spring Harbor Laboratory, Cold Spring Harbor, NY, USA, 2nd edition, 1989.

[14] M. A. Hassan, B. M. Haroun, A. A. Amara, and E. A. Serour, "Production and characterization of keratinolytic protease from new wool-degrading Bacillus species isolated from Egyptian ecosystem," BioMed Research International, vol. 2013, Article ID 175012, 14 pages, 2013.

[15] H. M. Abdou and M. A. Hassan, "Protective role of omega-3 polyunsaturated fatty acid against lead acetate-induced toxicity in liver and kidney of female rats," BioMed Research International, vol. 2014, Article ID 435857, 11 pages, 2014.

[16] F. Sanger, S. Nicklen, and A. R. Coulson, "DNA sequencing with chain-terminating inhibitors," Proceedings of the National
Academy of Sciences of the United States of America, vol. 74, no. 12, pp. 5463-5467, 1977.

[17] K. Tamura, D. Peterson, N. Peterson, G. Stecher, M. Nei, and S. Kumar, "MEGA5: molecular evolutionary genetics analysis using maximum likelihood, evolutionary distance, and maximum parsimony methods," Molecular Biology and Evolution, vol. 28, no. 10, pp. 2731-2739, 2011.

[18] L. D. Castro-Ochoa, C. Rodríguez-Gómez, G. Valerio-Alfaro, and R. O. Ros, "Screening, purification and characterization of the thermoalkalophilic lipase produced by Bacillus thermoleovorans CCR11," Enzyme and Microbial Technology, vol. 37, no. 6, pp. 648-654, 2005.

[19] A. A. Amara, M. A. Hassan, A. T. Abulhamd, and B. M. Haroun, "Non-mucoid $P$. aeruginosa aiming to a safe production of protease and lipase," International Science and Investigation Journal, vol. 2, no. 5, pp. 103-113, 2013.

[20] O. H. Lowry, N. J. Rosebrough, A. L. Farr, and R. J. Randall, "Protein measurement with the Folin phenol reagent," The Journal of Biological Chemistry, vol. 193, no. 1, pp. 265-275, 1951.

[21] A. Afsar and F. Cetinkaya, "Studies on the degreasing of skin by using enzyme in liming process," Indian Journal of Chemical Technology, vol. 15, no. 5, pp. 507-510, 2008.

[22] F. Shahidi, "Extraction and measurement of total lipids," in Current Protocols in Food Analytical Chemistry, John Wiley \& Sons, 2003.

[23] S. Elleuche, C. Schröder, K. Sahm, and G. Antranikian, "Extremozymes-biocatalysts with unique properties from extremophilic microorganisms," Current Opinion in Biotechnology, vol. 29, no. 1, pp. 116-123, 2014.

[24] M. Sifour, T. I. Zaghloul, H. M. Saeed, M. M. Berekaa, and Y. R. Abdel-Fattah, "Enhanced production of lipase by the thermophilic Geobacillus stearothermophilus strain-5 using statistical experimental designs," New Biotechnology, vol. 27, no. 4, pp. 330-336, 2010.

[25] Y. R. Abdel-Fattah, N. A. Soliman, S. M. Yousef, and E. R. El-Helow, "Application of experimental designs to optimize medium composition for production of thermostable lipase/ esterase by Geobacillus thermodenitrificans AZ1," Journal of Genetic Engineering and Biotechnology, vol. 10, no. 2, pp. 193200, 2012.

[26] M. G. Sánchez-Otero, I. I. Ruiz-López, D. E. Ávila-Nieto, and R. M. Oliart-Ros, "Significant improvement of Geobacillus thermoleovorans CCR11 thermoalkalophilic lipase production using Response Surface Methodology," New Biotechnology, vol. 28, no. 6, pp. 761-766, 2011.

[27] D. Sharma, B. K. Kumbhar, A. K. Verma, and L. Tewari, "Optimization of critical growth parameters for enhancing extracellular lipase production by alkalophilic Bacillus sp.", Biocatalysis and Agricultural Biotechnology, vol. 3, no. 4, pp. 205211, 2014.

[28] M. M. Berekaa, T. I. Zaghloul, Y. R. Abdel-Fattah, H. M. Saeed, and M. Sifour, "Production of a novel glycerol-inducible lipase from thermophilic Geobacillus stearothermophilus strain5," World Journal of Microbiology \& Biotechnology, vol. 25, no. 2, pp. 287-294, 2009.

[29] M. A. Eltaweel, R. N. Z. R. A. Rahman, A. B. Salleh, and M. Basri, "An organic solvent-stable lipase from Bacillus sp. strain 42," Annals of Microbiology, vol. 55, no. 3, pp. 187-192, 2005.

[30] L. Bora and M. Bora, "Optimization of extracellular thermophilic highly alkaline lipase from thermophilic Bacillus sp. isolated from hot spring of Arunachal Pradesh, India," Brazilian Journal of Microbiology, vol. 43, pp. 30-42, 2012. 
[31] S. Kumar, K. Kikon, A. Upadhyay, S. S. Kanwar, and R. Gupta, "Production, purification, and characterization of lipase from thermophilic and alkaliphilic Bacillus coagulans BTS-3," Protein Expression and Purification, vol. 41, no. 1, pp. 38-44, 2005.

[32] C. K. Sharma, P. K. Sharma, and S. S. Kanwar, "Optimization of production conditions of lipase from $B$. licheniformis MTCC10498," Research Journal of Recent Sciences, vol. 1, no. 7, pp. 2532, 2012.

[33] M. A. Abd El Rahman, Production of thermostable microbial enzymes for application in bio-detergent technology [M.S. dissertation], Faculty of Science, Al-Azhar University, Cairo, Egypt, 2006.

[34] V. R. Gayathri, P. Perumal, L. P. Mathew, and B. Prakash, "Screening and molecular characterization of extracellular lipase producing Bacillus species from coconut oil mill soil," International Journal of Science and Technology, vol. 2, no. 7, pp. 502-509, 2013.

[35] F. N. Niyonzima and S. S. More, "Concomitant production of detergent compatible enzymes by Bacillus flexus XJU-1," Brazilian Journal of Microbiology, vol. 45, no. 3, pp. 903-910, 2014.

[36] M. Veerapagu, A. S. Narayanan, K. Ponmurgan, and K. R. Jeya, "Screening, selection, identification, production, and optimization of bacterial lipase from oil spilled soil," Asian Journal of Pharmaceutical and Clinical Research, vol. 6, supplement 3, pp. 62-67, 2013. 

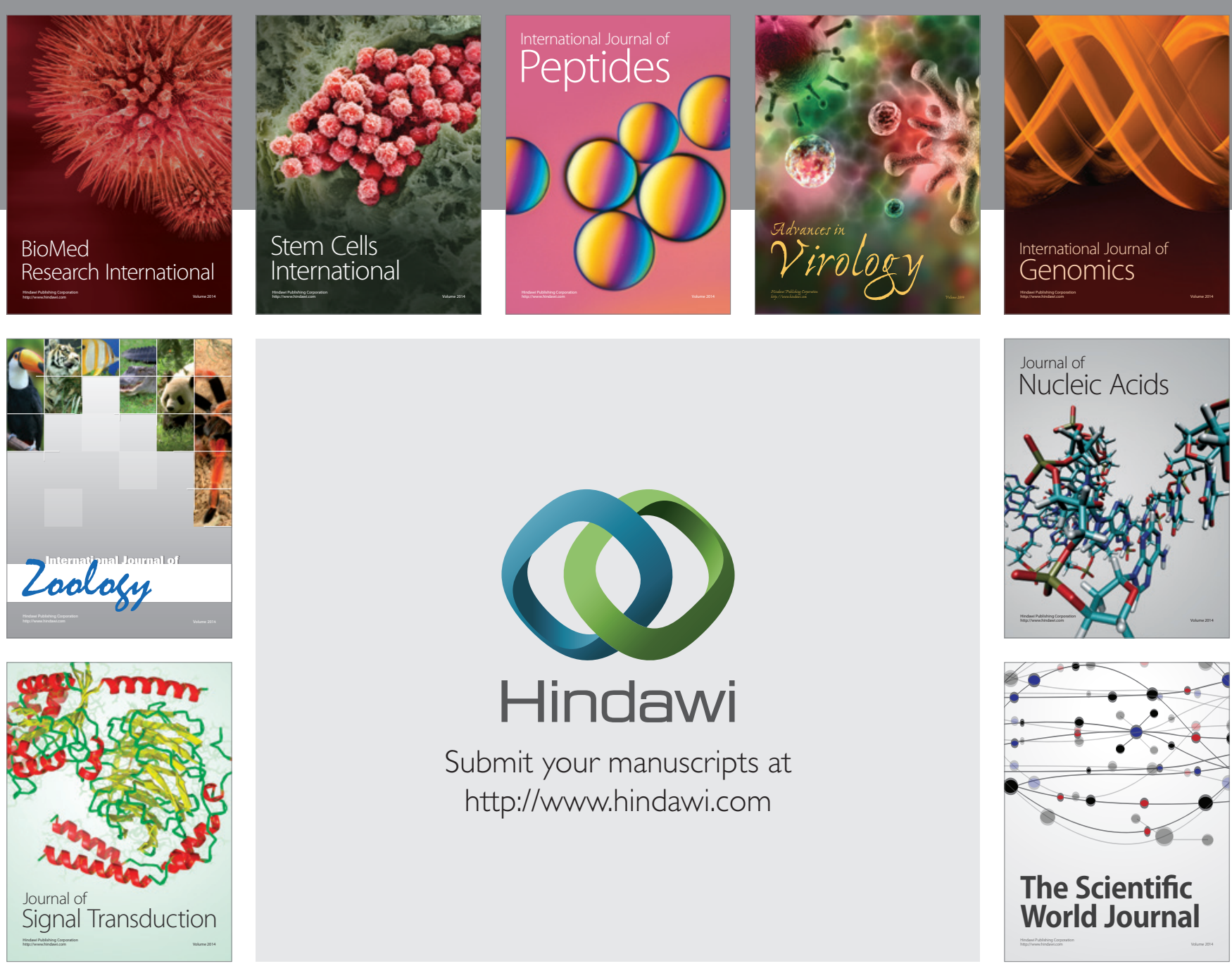

Submit your manuscripts at

http://www.hindawi.com
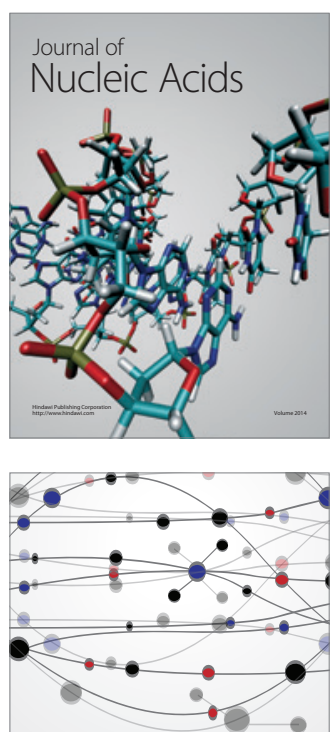

The Scientific World Journal
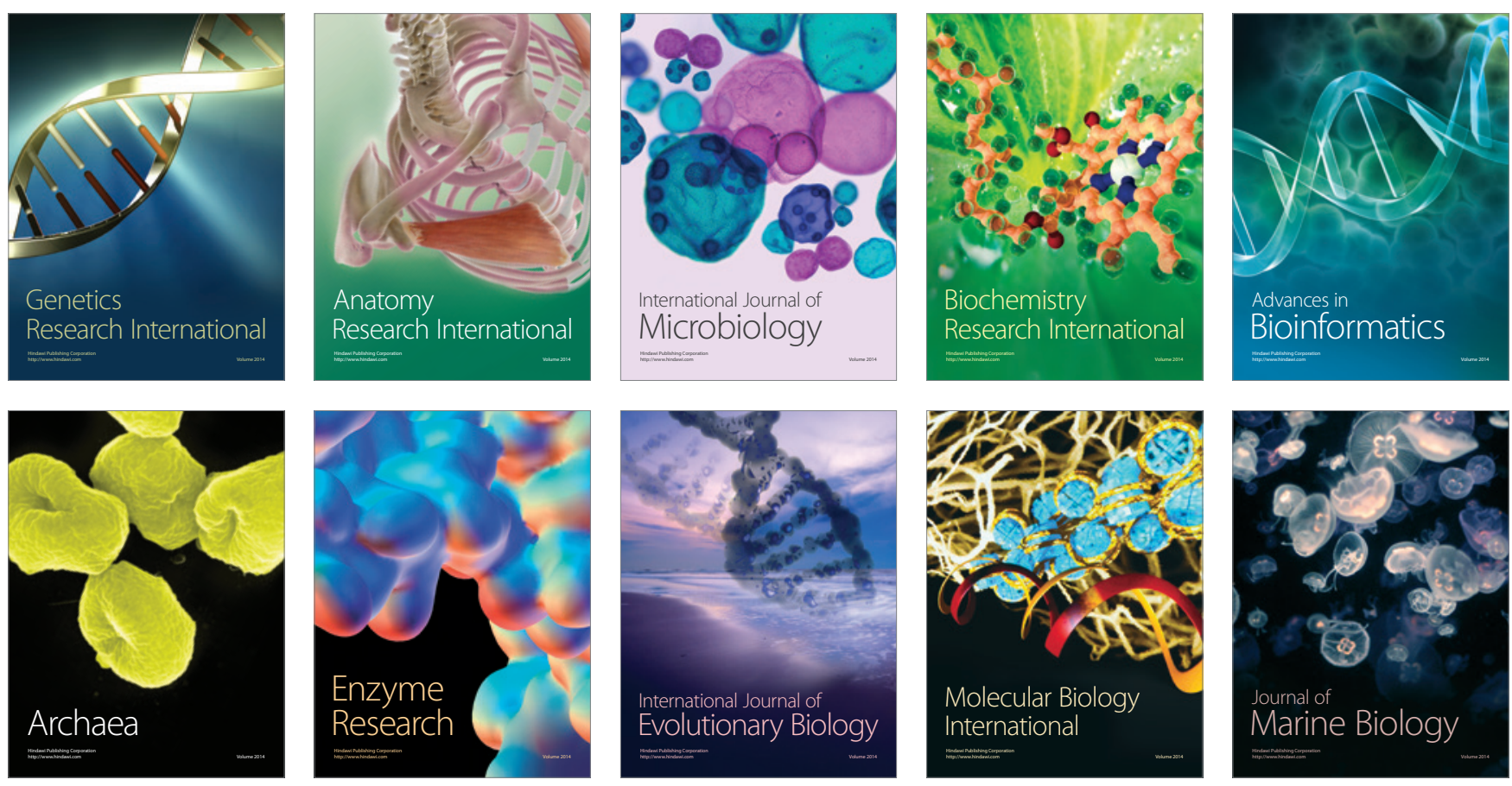